\title{
Notch Activation Modulates Bevacizumab Activity by CD44 Positive Cancer Stem Cells in Advanced Colon Cancer
}

Negri FV ${ }^{1 \# *}$, Bozzetti $C^{1 \#, ~ P e d r a z z i ~} G^{2}$, Azzoni $C^{3}$, Bottarelli $L^{3}$, Squadrilli $A^{1}$, Lagrasta $C^{4}$, Tamagnini $I^{5}$, Bisagni $A^{5}$, Ragazzi $M^{5}$, Madeddu $D^{6}$, Falco $A^{6}$, Gervasi $A^{6}$, Porzio $R^{7}$, Tomasello $G^{8}$, Leonardi $F^{1}$, Ardizzoni $A^{9}$, Sala $R^{4}$, Gnetti L ${ }^{10}$, Crafa $P^{10}$, Quaini $F^{6}$ and Cascinu $S^{11}$

${ }^{1}$ Medical Oncology Unit, University Hospital of Parma, Italy

${ }^{2}$ Department of Medicine and Surgery, Unit of Neuroscience, University of Parma, Italy

${ }^{3}$ Department of Biomedical, Biotechnological and Translational Sciences, Centre for Molecular and Translational Oncology (COMT), Unit of Pathological Anatomy, University

Hospital of Parma, Italy

${ }^{4}$ Department of Biomedical, Biotechnological and Translational Sciences, University of Parma, Italy

${ }^{5}$ Department of Pathology, Istituto di Ricerca e Cura a Carattere Scientifico (IRCCS), Santa Maria Nuova Hospital, Italy

${ }^{6}$ Department of Clinical and Experimental Medicine, University Hospital of Parma, Italy

${ }^{7}$ Medical Oncology Unit, Azienda Unità Sanitaria Locale, Italy

${ }^{8}$ Medical Oncology Unit, Azienda Istituti Ospitalieri, Italy

${ }^{9}$ Medical Oncology Unit, St Orsola-Malpighi University Hospital, Italy

${ }^{10}$ Pathologic Anatomy Unit, University Hospital of Parma, Italy

${ }^{11}$ Department of Medical and Surgical Sciences for Children and Adults, Division of Medical Oncology, University Hospital of Modena and Reggio Emilia, Italy \#Equally Contributed

\begin{abstract}
Background: Notch pathway is involved in regulating colon cancer stem cells (CSCs), which play an important role in angiogenesis and resistance to conventional therapies. CD44 and CD133 are transmembrane glycoproteins reported as putative markers for isolating CSCs. High expression of Notch Intracellular Cleaved Domain (NICD) has been associated with resistance to anti-vascular endothelial growth factor therapy. Based on these reports, we evaluated NICD, CD44 and CD133 expression in a series of consecutive metastatic colon cancer patients treated with bevacizumab-based chemotherapy within first-line clinical trials.
\end{abstract}

Methods: Histological samples obtained from 45 primary adenocarcinomas were tested by immunohistochemistry for NICD, CD44 and CD133. A scoring system based on staining intensity and percentage of stained cells was used. Vessels density was measured in hot-spot areas by CD31 antibody.

Results: CD44 levels were higher in high NICD cases than in low NICD cases (63\% vs. $16 \%$, respectively, $p=0.014)$. High NICD and CD44 levels predicted shorter progression-free $(p<0.001)$ and overall survival $(p=0.012)$. No significant association was found between CD133 or CD31 and NICD or CD44 expression.

Conclusion: Our data suggest that colon cancer patient with high NICD and CD44 levels have a reduced likelihood of response to bevacizumab-based therapy.

Keywords: Colorectal cancer; bevacizumab; Notch; CD44; Stem cells; Angiogenesis

\section{Introduction}

Vascular endothelial growth factor (VEGF)-targeted agents improve the survival of advanced colorectal cancer (CRC) patients, [13] but their activity is restricted by mechanisms of both primary and adaptive resistance [4].

Even within an individual patient, tumor contains cell populations with different genetic mutations and at various stages of differentiation, both contributing to cancer cell heterogeneity. In addition, a small fraction of cells is maintained in an undifferentiated stage and defined as "cancer stem cells (CSCs)" with properties including self-renewal, multipotentiality and apoptosis resistance. Recent data from the literature suggest that CRC may originate from this pool of CSCs that may account for tumor heterogeneity [5-10] and resistance to anticancer treatments $[11,12]$. Therefore, understanding the characteristics of CSCs may lead to novel findings in individualized treatment. Moreover, intestinal stem cells are located near the base of crypts [5] and are believed to have a relatively longer life span compared with the normal intestinal epithelial cell; hence, this specific population is potentially exposed to and is able to harbour genetic alterations that are critical mediator of oncogenesis.

CD133 and CD44 are well-established putative cancer stem cell biomarkers expressed in CRC [13-16]. CD133 is a surface transmembrane glycoprotein whose expression is mainly correlated with tumorigenicity, metastasis, and worse prognosis [17]. CD44, a hyaluronic receptor, promotes cell-adhesion and assembly of cell surface growth factors specifically involved in the maintenance of cellmatrix interactions [14]. CD44 up-regulation increases tumor growth and anti-apoptotic property [16]. It has been demonstrated that colon cancer cell lines expressing both high levels of CD44 and CD133 had more stem cell-related genes, and displayed increased tumorigenic ability. A subset of SW480 cell lines showed enhanced CD44 expression and other markers of chemoresistance [14-18]. Therefore, both CD133 and CD44 could have a strong potential as targets for drug therapies in CRC. These markers are also correlated with the downstream

*Corresponding author: Francesca V. Negri, Medical Oncology Unit, University Hospital, Via Gramsci 14, 43126 Parma, Italy, Tel: 0039 0521702676; Fax: 0039 0521995448; E-mail: francescanegri2@hotmail.com

Received July 14, 2017; Accepted September 12, 2017; Published September 14, 2017

Citation: Negri FV, Bozzetti C, Pedrazzi G, Azzoni C, Bottarelli L, et al. (2017) Notch Activation Modulates Bevacizumab Activity by CD44 Positive Cancer Stem Cells in Advanced Colon Cancer. J Mol Biomark Diagn S2: 036. doi:10.4172/2155 9929.S2-036

Copyright: (C 2017 Negri FV, et al. This is an open-access article distributed under the terms of the Creative Commons Attribution License, which permits unrestricted use, distribution, and reproduction in any medium, provided the original author and source are credited 
molecular pathways that accomplish oncogenic activities such as Wnt, Notch, and BMP-1 [19].

Notch signalling plays a pivotal role for maintenance of the population of colon tumor-initiating cells, a CSC population that retains high metastatic potential and self-renewal $[20,21]$. When the Notch receptor binds its ligands, the cytoplasmic portion of Notch undergoes proteolitic cleavage through $\gamma$ secretase [22]. The free cytosolic portion (Notch intracellular domain (NICD)) translocates to the nucleus where it interacts with a multiprotein complex to induce the transcription of Notch target genes [23]. Preclinical studies [24] and a clinical study from our group [25] showed that NICD overexpression is associated with resistance to anti-vascular endothelial growth factor (VEGF) therapy in colon cancer. Based on these observations, we evaluated the immunohistochemical expression of CD44 and CD133 in a series of consecutive metastatic colon cancer patients tested for NICD and treated with anti-VEGF monoclonal antibody (mAb) bevacizumab within first-line clinical trials. Moreover, to determine whether intratumor microvessel density (MVD) could represent a confounding variable of resistance to bevacizumab, the expression of the endothelial cell marker CD31 was assessed.

\section{Materials and Methods}

\section{Patients}

The study population consisted of consecutive patients with histologically confirmed mCRC enrolled into four prospective clinical trials assessing first-line bevacizumab-based regimens at four Institutions between 2005 and 2011 [26-29]. No patients with mucinous histology ( $>50 \%$ extracellular mucin) were included in the study. The objectives of the study were to evaluate NICD, CD44 and CD133 expression in advanced CRC patients treated with bevacizumab and to correlate these markers with objective tumor response to bevacizumab, progression-free survival (PFS) and overall survival (OS). Inclusion criteria were: available adequate archival tumor samples and measurable disease according to Response Evaluation Criteria in Solid Tumors (RECIST; version 1.1) [30].

According to treatment protocol, patients were treated with bevacizumab in combination with either infusional fluorouracil, leucovorin and irinotecan (FOLFIRI) or infusional fluorouracil, leucovorin and oxaliplatin (FOLFOX4) or infusional fluorouracil, leucovorin, oxaliplatin and irinotecan (FOLFOXIRI) or capecitabine. Patients received bevacizumab at the dose of $5 \mathrm{mg} / \mathrm{kg}$ on day 1 given every 2 weeks or $7.5 \mathrm{mg} / \mathrm{kg}$ on day 1 given every 3 weeks until disease progression, unacceptable toxic effects or withdrawal of consent. This study was conducted according to a protocol approved by the institutional review board/independent ethics committee and informed consent was obtained from patients for the use of tissue samples and the analysis of clinical information.

The response to treatment was evaluated according to RECIST 1.1 [30], taking into account the number of target lesions, sum of the diameters of the target lesions, percentage change since the baseline or tumor nadir (whichever was the least preceding sum diameter), descriptions of nontarget lesions, presence or absence of new lesions.

\section{Immunohistochemistry}

Formalin-fixed, paraffin-embedded tissue blocks from pretreatment primary lesions, selected on the basis of quality and representativeness of the sample, were cut into $5 \mu \mathrm{m}$ thick sections and incubated overnight at $4^{\circ} \mathrm{C}$ with the primary antibody. The antibodies used in this study were: NICD polyclonal antibody (Val1744) (Cell Signaling Technology, Danvers, MA, USA), CD44 monoclonal antibody (mAb) (clone DF1485; Dako, Glostrup, Denmark), CD133 mAb (clone AC133; Miltenyi Biotec, Bergisch Gladbach, Germany) and CD31 mAb (clone JC70; Ventana-Roche, Tucson, AZ, USA). Antibody detection was performed using an ADVANCE HRP Link and an ADVANCE HRP Enzyme (Dako Corp., CA, USA). Diaminobenzidine (DAB) was used as chromogen. Samples were counterstained with haematoxylin eosin solution.

NICD and CD44 expression were quantified using a semiquantitative scoring system based on intensity and on percentage of immunostained cells. The immunohistochemical staining was scored as 0 when no expression was found, $1+, 2+$ and $3+$ when weakly, moderately and strongly positive expression was respectively observed in $\geq 10 \%$ of the cells. NICD and CD44 expression was judged positive when a strong staining ( $3+$ ) was found in $>50 \%$ and $\geq 60 \%$ of cells, respectively. CD133 was evaluated by assessing positive tumor glands compared to all tumor glands. CD133 immunohistochemical staining was scored as 0 when there was no expression at all, $1+, 2+$ and $3+$ when a weak, moderate and strong expression was respectively detected in $\geq$ $10 \%$ of the whole tumor area. Tumors with $2 / 3+$ intensity in $\geq 10 \%$ of the whole tumor area were considered as positive.

Vessel density was evaluated after scanning the immunostained section at 200x magnification in order to identify the tumor areas with the highest number of microvessels (hotspots) positively stained by CD31 antibody. Microvessel count was performed from a minimum of 4 to a maximum of 12 fields depending on the cellularity of the tumor at $400 \mathrm{x}$ magnification corresponding to an area of $2.3 \mathrm{~mm}^{2}$ per field. For each sample, the mean value of vessel count in four fields with the highest MVD was retained as the final value. Any single endothelial cell or cluster that stained for CD31 was counted as a single microvessel, even in the absence of a visible vascular lumen.

Two observers blinded to the clinical and pathological data evaluated all immunohistochemical staining.

\section{Statistical analysis}

Statistical significance was set at $\mathrm{p}<0.05$ for each analysis; all analyses were carried out using IBM-SPSS Statistical package, version 22.0 and the widespread open source statistical system ' $R$ ', version '3.3.1'. Correlations between interval and ordinal variables were evaluated by Pearson's and Spearman's correlation coefficients, while associations between nominal or dichotomized variables and clinical outcome parameters were estimated by chi-square test and Fisher exact test for 2 $\times 2$ tables. The Kaplan-Meier method was used to estimate median OS and PFS measured from the date of randomization for all patients. Cox proportional hazard models were fitted to investigate the associations between OS and PFS and covariates. Variables included were: KRAS status, chemotherapy protocol, second-line chemotherapy, NICD expression, CD44 expression, CD133 expression, CD31 expression and MVD. Results were expressed as hazard-ratios (HRs) with $95 \%$ confidence intervals (CIs). All tests were two-sided.

Receiver operating characteristic (ROC) curve analysis was carried out to determine a possible cut-off point for CD44 level; for each value, sensitivity, specificity, and total accuracy were obtained as percentages.

\section{Results}

Forty-five colon cancer patients with advanced adenocarcinoma, involved into four prospective clinical trials assessing first-line bevacizumab-based regimens, were enrolled in this study. Histological 
Citation: Negri FV, Bozzetti C, Pedrazzi G, Azzoni C, Bottarelli L, et al. (2017) Notch Activation Modulates Bevacizumab Activity by CD44 Positive Cancer Stem Cells in Advanced Colon Cancer. J Mol Biomark Diagn S2: 036. doi:10.4172/2155-9929.S2-036

samples were obtained from 7 biopsies and 38 surgical specimens. Table 1 shows patients' characteristics. NICD immunostaining showed a predominant cytoplasmic localization (Figure 1A). Eight of the 45 (18\%) patients showed high levels of NICD expression as defined by a NICD score $3+$ in $>50 \%$ of tumor cells [25]. Among patients with low levels of NICD expression, 2 exhibited a completely negative staining, 9 were scored as $1+$ and 26 as $2+$.

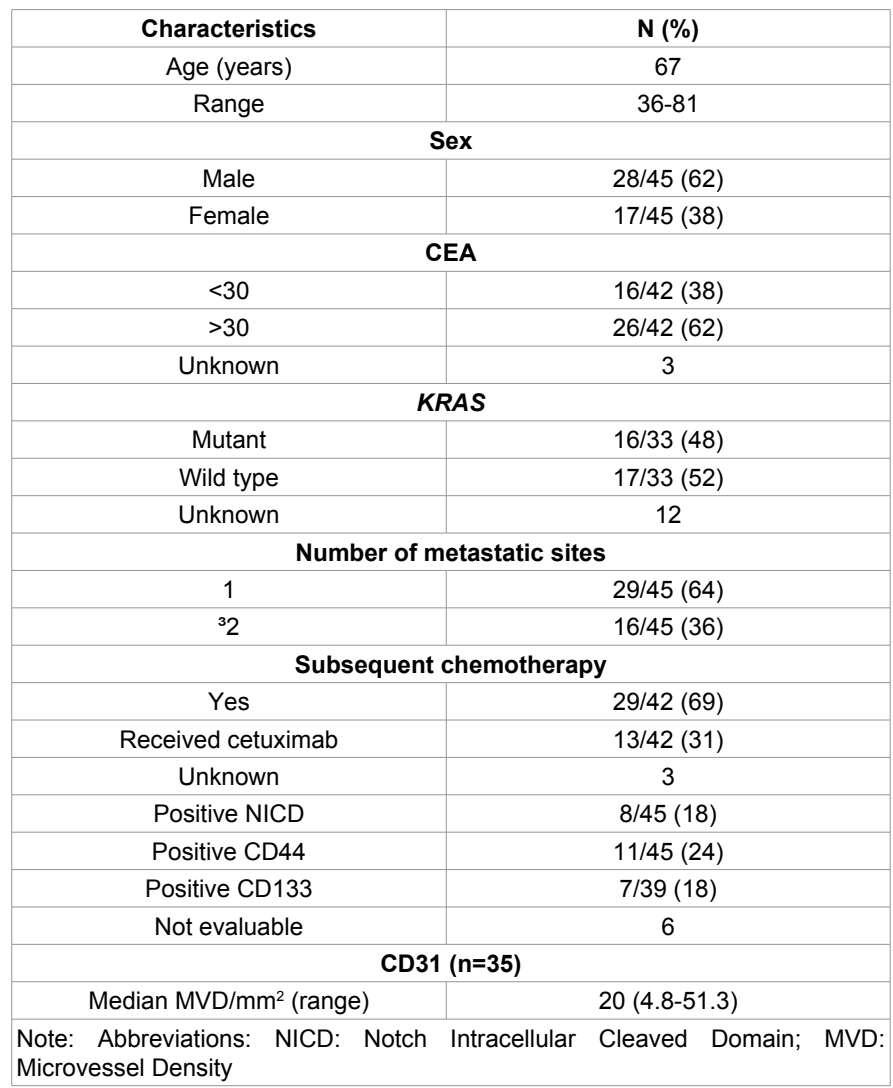

Table 1: Patients' characteristics.

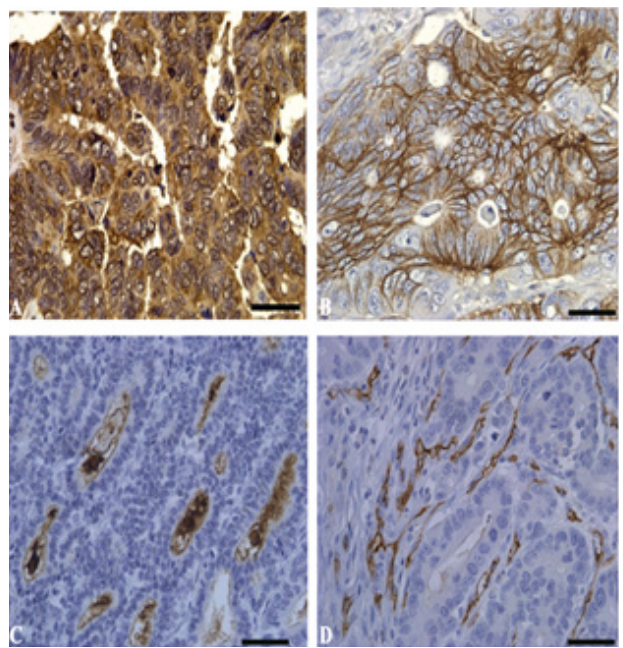

Figure 1: Immunohistochemical detection of Notch intracellular cleaved domain (NICD), CD44, CD133 and CD31 proteins in colon carcinoma. Representative images of NICD cytoplasmic reactivity (A), CD44 restricted to the cell membrane (B), CD133 on the luminal cell surface of tumor glands (C) and CD31 labelling of vascular endothelial cells (D). Scale bars $=50 \mu \mathrm{m}$.

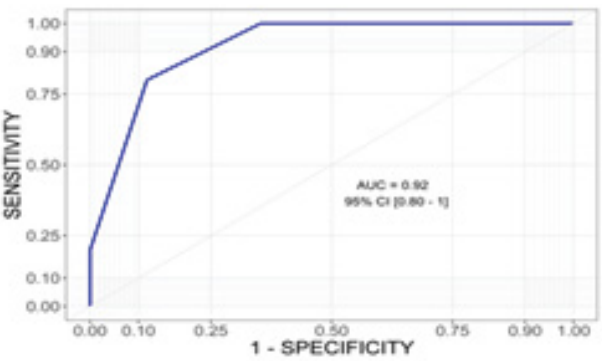

Figure 2: Receiver operating characteristic (ROC) curve for CD44. Analysis relative to logistic model based on CD44 positive staining, with objective tumor response to bevacizumab.

\begin{tabular}{|c|c|c|}
\hline Variables & Low NICD & High NICD \\
\hline Low CD44 & 31 & 3 \\
\hline High CD44 & 6 & 5 \\
\hline Fisher's exact test $\mathrm{p}=0.014$ & \\
\hline Note: Abbreviation: NICD: Notch intracellular cleaved domain \\
\hline
\end{tabular}

Table 2: Association between CD44 and NICD expression in colon cancer patients.
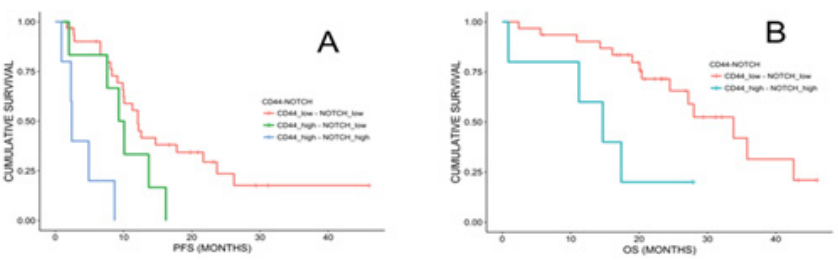

Figure 3: Progression-free survival (A) and overall survival (B) according to Notch intracellular cleaved domain (NICD) and CD44 status.

Immunohistochemical staining for CD44 showed membrane localization of the protein in epithelial tumor cells in the vast majority of cases (Figure 1B). The cut off value for CD44 level, as determined by ROC curve, was $\geq 60 \%$ of tumor cells showing $3+$ intensity and this threshold was used to divide patients in two groups of 'high' and 'low' CD44 expression. Eleven (24\%) of the 45 cases showed a high CD44 expression.

CD133 was evaluable in 39 of 45 cases; 4 cases were not included for technical reasons (suboptimal staining) and two biopsy samples were inadequate. CD133 expression was localized to the glandular-luminal surface of neoplastic glands and on intraglandular cell debris (Figure 1C). Dot-like cytoplasmic staining was occasionally present. Positive CD133 expression was found in 7 of 39 cases (18\%) and only 2 cases showed more than $30 \% \mathrm{CD} 133$ positive cells.

Thirty-five of the 45 samples were evaluable for CD31 expression (among the 10 unassessable cases, 7 were biopsies and 3 had the paraffin block run out). Positive CD31 staining was localized to vascular endothelial cells (Figure 1D). The value of MVD observed in the 35 evaluable samples ranged from 11 to 118 at $40 \mathrm{x}$ magnification, with a median value of 20 per $\mathrm{mm} 2$ (range: $4.8-51.3$ ).

CD44 immunostaining (3+) in $\geq 60 \%$ of tumor cells emerged as the best cut-off value to discriminate responders vs nonresponders to bevacizumab (Figure 2). A positive association was found between NICD and CD44 expression (Table 2). Log-rank test showed both a significant shorter PFS $(\mathrm{p}<0.001)$ and OS $(\mathrm{p}=0.012)$ for patients having both high NICD and CD44 expression (Figure 3). A median PFS of 12.1 months in low NICD and CD44 expressing tumors was observed 


\begin{tabular}{|c|c|c|c|c|}
\hline \multirow{2}{*}{ Variables } & \multicolumn{2}{|c|}{ PFS } & \multicolumn{2}{c|}{ OS } \\
\cline { 2 - 5 } & HR (95\% Cl) & p-value & HR (95\% CI) & p-value \\
\hline $\begin{array}{c}\text { NICD-Low; } \\
\text { CD44-Low }\end{array}$ & Reference value & 0.001 & Reference value & 0.050 \\
\hline $\begin{array}{c}\text { NICD-Low; } \\
\text { CD44-High }\end{array}$ & $\begin{array}{c}2.163(0.851- \\
5.495)\end{array}$ & 0.105 & $\begin{array}{c}1.875(0.671- \\
5.239)\end{array}$ & 0.231 \\
\hline $\begin{array}{c}\text { NICD-High; } \\
\text { CD44-Low }\end{array}$ & $\begin{array}{c}1.783(0.412- \\
7.712)\end{array}$ & 0.439 & $\begin{array}{c}4.098(0.878- \\
19.13)\end{array}$ & 0.073 \\
\hline $\begin{array}{c}\text { NICD-High; } \\
\text { CD44-High }\end{array}$ & $\begin{array}{c}9.194(2.996- \\
28.22)\end{array}$ & $<0.001$ & $\begin{array}{c}4.157(1.312- \\
13.17)\end{array}$ & 0.015 \\
\hline
\end{tabular}

Abbreviations: NICD: Notch Intracellular Cleaved Domain; HR: Hazard Ratio; $\mathrm{Cl}$ : Confidence Interval

Table 3: Cox's regression for progression-free survival (PFS) and overall survival (OS) relative to NICD and CD44 expression.

\begin{tabular}{|l|c|c|c|c|}
\hline Variables & $\begin{array}{c}\text { Low } \\
\text { CD31 }\end{array}$ & High CD31 & $\begin{array}{c}\text { Low } \\
\text { CD133 }\end{array}$ & High CD133 \\
\hline Low CD44 & 11 & 10 & 16 & 5 \\
\hline High CD44 & 11 & 8 & 22 & 2 \\
\hline \multicolumn{2}{|r|}{ Fisher's exact test, $\mathrm{p}=0.76$} & \multicolumn{2}{|c|}{ Fisher's exact test, $\mathrm{p}=0.22$} \\
\hline Low NICD & 16 & 14 & 28 & 6 \\
\hline High NICD & 6 & 4 & 10 & 1 \\
\hline \multicolumn{2}{|r|}{ Fisher's exact test, $\mathrm{p}=1$} & \multicolumn{2}{|c|}{ Fisher's exact test, $\mathrm{p}=0.66$} \\
\hline
\end{tabular}

Abbreviation: NICD: Notch intracellular cleaved domain

Table 4: Expression of CD31 and CD133 in relation to CD44 and NICD in colon cancer patients.

compared to 2.4 months in high NICD and CD44 tumors. Likewise, a median OS of 30.4 months was observed in low NICD and CD44 cases compared to 14.7 months in high NICD and CD44 cases.

Cox regression following univariate analysis confirmed that both NICD and CD44 were significantly associated with PFS and OS outcome. Table 3 shows that HR increases significantly from low NICD and CD44 levels to high NICD and CD44 levels.

All major clinical characteristics were comparable among subgroups of patients (data not shown). In particular, no differences were noticed for age, baseline levels of CEA, KRAS status, number of metastatic sites and subsequent chemotherapy.

Cox regression didn't show any significant association between CD133 and CD31 expression and MVD with PFS and OS. Moreover, we didn't find any significant association of CD133 and CD31 expression with CD44 and NICD levels (Table 4).

\section{Discussion}

We previously showed that high NICD expression in advanced CRC was negatively associated with response to the VEGF-targeted $\mathrm{mAb}$ bevacizumab [25]. Interestingly, in patients treated with chemotherapy alone, survival analysis did not show differences between high and low NICD levels, thus indicating a predictive rather than prognostic value of this molecular marker. Our results were in line with those by Paiva et al. [31], in which low Notch1 levels were able to predict improved OS in a series of 105 metastatic CRC patients treated with chemotherapy plus bevacizumab.

Notch signalling is known to be essential for stem cell maintenance [20]. The deregulated expression of Notch proteins, ligands and targets alters self-renewal and cell fate of stem cells that are normally controlled by both intrinsic and extrinsic pathways resulting in stem cell expansion. For example, Notch signalling is highly active in hematopoietic stem cells (HSC) compared to more differentiated cells and inhibition of Notch signalling promotes differentiation of HSC
[32]. Notch component genes are mainly localized in the base of colonic crypts further indicating that activation of Notch signalling may be involved in the regulation of colonic stem cells [33]. CD44 is critical for proper cell homing to niches microenvironment and for maintaining CSCs in a stem-like state [34,35]. In our series, high levels of NICD expression, evaluated on tissue sections from advanced colon tumors, were significantly associated with high CD44 levels in the majority of cases. Moreover, high NICD and CD44 expression was associated with unfavourable prognosis in patients treated with bevacizumab-based therapy. In pancreatic cancer, subpopulation of quiescent cells [36], enriched of CSCs markers such as CD44 and CD24, can escape therapy and subsequently induce tumor regrowth. Moreover, it has been demonstrated that after chemotherapy CSCs show a relative increase rather than decrease [37], pointing out that a better characterization of CSCs could help in targeting this population in order to inhibit cancer growth and metastasis.

Our results do not seem to support CD133 as a prognostic marker for colon CSCs. CD133 has been reported as a CRC CSC marker based on its high tumorigenicity in immunodeficient mice [6,7]. However, it should be noted that, in accordance with previous literature $[38,39]$, in present study the majority of colon cancers lack the expression of CD133 and that CD133 and CD44 were not detected on the same tumor region. Moreover, it has been reported that knockdown of CD44, but not CD133, strongly prevents tumor initiation in vivo [38].

MVD assessment is the most commonly used method to quantify intratumoral angiogenesis in cancer. Vasculogenesis triggered by Notch signalling activation increases blood perfusion and reduce necrosis and hypoxia, leading to a decreased VEGF production and a reduced tumor dependency on VEGF. However, the relationship between Notch and VEGF pathways is not completely defined. Many retrospective studies reported that MVD is inversely related to survival in CRC, but other studies did not reach this conclusion [40]. Our results do not support a prognostic role of MVD in advanced colon cancer patients.

Although this analysis is subject to the limitations of a retrospective study, we utilized data from prospective randomized trials, each of which studied similar patient populations treated with bevacizumabbased chemotherapy. In order to minimize further bias, colon cancers of the mucinous histotype were excluded, given that metaanalyses and previous works suggest that mucinous adenocarcinomas may be associated with worse outcome compared with classical adenocarcinomas [41] as well as with poorer response to chemotherapy [42]. This study design strengthens our findings.

\section{Conclusion}

In conclusion, our results suggest that Notch is probably an important regulator for colonic stem cells and support a potential role of stem cells in colon cancer resistance to anti-VEGF therapy. Further studies are needed to clarify the regulatory role of Notch signalling in colon CSCs to provide a rational basis for novel therapeutic approaches to overcome antiangiogenic resistance.

\section{References}

1. Hurwitz H, Fehrenbacher L, Novotny W, Cartwright T, Hainsworth J, et al (2004) Bevacizumab plus irinotecan, fluorouracil, and leucovorin for metastatic colorectal cancer. N Engl J Med 350: 2335-2342.

2. Burger RA, Brady MF, Bookman MA, Fleming GF, Monk BJ, et al. (2011) Incorporation of bevacizumab in the primary treatment of ovarian cancer. $N$ Engl J Med 365: 2473-2483.

3. Perren TJ, Swart AM, Pfisterer J, Ledermann JA, Pujade-Lauraine E, et al (2011) A phase 3 trial of bevacizumab in ovarian cancer. N Engl J Med 365 2484-2496. 
Citation: Negri FV, Bozzetti C, Pedrazzi G, Azzoni C, Bottarelli L, et al. (2017) Notch Activation Modulates Bevacizumab Activity by CD44 Positive Cancer Stem Cells in Advanced Colon Cancer. J Mol Biomark Diagn S2: 036. doi:10.4172/2155-9929.S2-036

Page 5 of 8

4. Bergers G, Hanahan D (2008) Modes of resistance to anti-angiogenic therapy. Nat Rev Cancer 8: 592-603.

5. Zeuner A, Todaro M, Stassi G, De Maria R (2014) Colorectal cancer stem cells: From the crypt to the clinic. Cell Stem Cell 15: 692-705.

6. O'Brien CA, Pollett A, Gallinger S, Dick JE (2007) A human colon cance cell capable of initiating tumor growth in immunodeficient mice. Nature 445 : 106-110.

7. Ricci-Vitiani L, Lombardi DG, Pilozzi E, Biffoni M, Todaro M, et al. (2007) Identification and expansion of human colon-cancer-initiating cells. Nature 445 : $111-115$.

8. Todaro M, Alea MP, Di Stefano AB, Cammareri P, Vermeulen L, et al. (2007) Colon cancer stem cells dictate tumor growth and resist cell death by production of interleukin-4. Cell Stem Cell 1: 389-402.

9. Todaro M, Gaggianesi M, Catalano V, Benfante A, lovion F, et al. (2014) CD44v6 is a marker of constitutive and reprogrammed cancer stem cells driving colon cancer metastasis. Cell Stem Cell 14: 342-356.

10. De sousa-E-melo F, Vermeulen L, Fessler E, Medema JP (2013) Cancer heterogeneity-A multifaceted view. Embo Rep 14: 686-695.

11. Yang D, Wang $\mathrm{H}$, Zhang J, Li C, Lu Z, et al. (2013) In vitro characterization of stem cell-like properties of drug-resistant colon cancer subline. Oncol Res 21: $51-57$

12. Xie ZY, Lv K, Xiong Y, Guo WH (2014) ABCG2-meditated multidrug resistance and tumor- initiating capacity of side population cells from colon cancer. Oncol Res Treat 37: 666-668, 670-672.

13. Jin-Yong Z, Min C, Long M, Xiaoxiao W, Yu-Gen C, et al. (2016) Role of CD44high/CD133high HCT-116 cells in the tumorigenesis of colon cancer. Oncotarget 7: 7657-7666.

14. Sahlberg SH, Spiegelberg D, Glimelius B, Stenerlöw B, Nestor M (2014) Evaluation of cancer stem cell markers CD133, CD44, CD24: Association with AKT isoforms and radiation resistance in colon cancer cells. PLoS ONE 9: e94621.

15. Zhou JY, Chen M, Ma L, Wang X, Chen YG, et al. (2016) Role of CD44 (high)/ CD133(high) HCT-116 cells in the tumorigenesis of colon cancer. Oncotarget 7: 7657-7666.

16. Schneider M, Huber J, Hadaschik B, Siegers GM, Heinz- Herbert F, et al. (2012) Characterization of colon cancer cells: A functional approach characterizing CD133 as a potential stem cell marker. BMC Cancer 12: 96-107.

17. Chen S, Song X, Chen Z, Li X, Li M, et al. (2013) CD133 expression and the prognosis of colorectal cancer: A systematic review and meta-analysis. PLoS One 8: e56380.

18. Xiong B, Ma L, Hu X, Zhang C, Cheng Y (2014) Characterization of side population cells isolated from the colon cancer cell line SW480. Int J Oncol 45: 1175-1183.

19. Mikhail S, Zeidan A (2014) Stem cells in gastrointestinal cancers: The road less travelled. World J Stem Cells 6: 606-613.

20. Fre S, Huyghe M, Mourikis P, Robine S, Louvard D, et al. (2005) Notch signals control the fate of immature progenitor cells in the intestine. Nature 435: 964-968.

21. Sikandar SS, Pate KT, Anderson S, Dizon D, Edwards RA, et al. (2010) Notch signaling is required for formation and self-renewal of tumor-initiating cells and for repression of secretory cell differentiation in colon cancer. Cancer Res 70 $1469-1478$.

22. Hori K, Sen A, Artavanis-Tsakonas S (2013) Notch signaling at a glance. J Cell Sci 126: 2135-2140.

23. Kopan R, Ilagan MX (2009) The canonical Notch signaling pathway: Unfolding the activation mechanism. Cell 137: 216-233

24. Li JL, Sainson RC, Oon CE, Turley H, Leek R, et al. (2011) DLL4-Notch signaling mediates tumor resistance to anti-VEGF therapy in vivo. Cancer Res 71: 6073-6083.

25. Negri FV, Crafa P, Pedrazzi G, Bozzetti C, Lagrasta C, et al. (2015) Strong Notch activation hinders bevacizumab efficacy in advanced colorectal cancer. Future Oncol 11: 3167-3174.

26. Sobrero A, Ackland S, Clarke S. Perez-Carrión R, Chiara S, et al. (2009) Phase IV study of bevacizumab in combination with infusional fluorouracil, leucovorin and irinotecan (FOLFIRI) in first-line metastatic colorectal cancer. Oncology 77: 113-119.

27. Loupakis F, Cremolini C, Masi G, Lonardi S, Zagonel V, et al. (2014) Initial therapy with FOLFOXIRI and bevacizumab for metastatic colorectal cancer. N Engl J Med 371: 1609-1618.

28. Passardi A, Scarpi E Cavanna L, Fontana A, Vertogen B, et al. (2013) Effectiveness of bevacizumab added to gold standard chemotherapy in metastatic colorectal cancer $(\mathrm{mCRC})$ : final results from the Itaca randomized clinical trial. J Clin Oncol 31: 3517.

29. Cunningham D, Lang I, Marcuello E, Lorusso V, Ocvirk J, et al. (2013) Bevacizumab plus capecitabine versus capecitabine alone in elderly patients with previously untreated metastatic colorectal cancer (AVEX): An open-label, randomized Phase 3 trial. Lancet Oncol 14: 1077-1085.

30. Eisenhauer EA, Therasse P, Bogaerts J, Schwartz LH, Sargent D, et al. (2009) New response evaluation criteria in solid tumors: Revised RECIST guideline (version 1.1). Eur J Cancer 45: 228-247.

31. Paiva TF Jr, De Jesus VH, Marques RA, Da Costa AA, De Macedo MP, et al. (2015) Angiogenesis-related protein expression in bevacizumab-treated metastatic colorectal cancer: Notch1 detrimental to overall survival. BMC Cancer 15: 643

32. Duncan AW, Rattis FM, DiMascio LN, Congdon KL, Pazianos G, et al. (2005) Integration of Notch and Wnt signaling in hematopoietic stem cell maintenance. Nat Immunol 6: 314-322.

33. Kosinski C, Li VS, Chan AS, Zhang J, Ho C, et al. (2007) Gene expression patterns of human colon tops and basal crypts and BMP antagonists as intestinal stem cell niche factors. Proc Natl Acad Sci USA 104: 15418-15423.

34. Jin L, Hope KJ, Zhai Q, Smadja-Joffe F, Dick JE (2006) Targeting of CD44 eradicates human acute myeloid leukemia stem cells. Nat Med 12: 1167-1174.

35. Calabrese C, Poppleton H, Kocak M, Hogg TL, Fuller C, et al. (2007) A perivascular niche for brain tumor stem cells. Cancer Cell 11: 69-82.

36. Dembinski JL, Krauss S (2009) Characterization and functional analysis of a slow cycling stem cell-like subpopulation in pancreas adenocarcinoma. Clin Exp Metastasis 26: 611-623.

37. Li X, Lewis MT, Huang J, Gutierrez C, Osborne CK, et al. (2008) Intrinsic resistance of tumorigenic breast cancer cells to chemotherapy. J Natl Cance Inst 100: 672-679.

38. Du L, Wang H, He L, Zhang J, Ni B, et al. (2008) CD44 is of functional importance for colorectal cancer stem cells. Clin Cancer Res 14: 6751-6760.

39. Kojima M, Ishii G, Atsumi N, Fujii S, Saito N, et al. (2008) Immunohistochemical detection of CD133 expression in colorectal cancer: A clinicopathological study. Cancer Sci 99: 1578-1583.

40. Des Guetz G, Uzzan B, Nicolas P, Cucherat M, Morere JF, et al. (2006) Microvessel density and VEGF expression are prognostic factors in colorecta cancer. Meta-analysis of the literature. Br J Cancer 94: 1823-1832.

41. Verhulst J, Ferdinande L, Demetter P, Ceelen W (2012) Mucinous subtype as prognostic factor in colorectal cancer: A systematic review and meta-analysis. J Clin Pathol 65: 381-388.

42. Negri FV, Wotherspoon A, Cunningham D, Norman AR, Chong G, et al. (2005) Mucinous histology predicts for reduced fluorouracil responsiveness and survival in advanced colorectal cancer. Ann Oncol 16: 1305-1310.
This article was originally published in a special issue, Cancer Biomarkers handled by Editor(s). Dr. Sudhir Srivastava, Cancer Biomarkers Research Group, National Institute of Health, USA; Dr. Shou-Jiang Gao, The University of Texas Health Science Centre at San Antonio, USA; Dr. Kenneth Maiese, University of Medicine \& Dentistry of New Jersey, New Jersey Medical School, USA 